\title{
Hubungan Postur Kerja dan Getaran Mekanis dengan Keluhan Musculoskeletal Disorder Pekerja PT. BMSTI
}

\author{
Yulia Sari ${ }^{\star}$, Perdani Ningrum dan Isna Qadrijati \\ Fakultas Kedokteran, Universitas Sebelas Maret, Surakarta, Indonesia \\ *corresponding author, e-mail: yuliasari_fk@staff.uns.ac.id
}

Received: 07/08/2019; published: 11/02/2020

\begin{abstract}
Background: one of the problems related to the health of workers is musculoskeletal disorder. Risk factors for musculoskeletal disorders include occupational posture and mechanical vibration. This study investigates the relationship between musculoskeletal disorder complaints with work posture and mechanical vibration. Method: The study aims to determine the relationship between work posture and the incidence of musculoskeletal disorders. This research is an observational analysis with cross-section approaches, samples of this research using the total working population of 110 units of spinning workers in the PT Bintang Makmur Sentosa Textile Industry (BMSTI). Data collection techniques with observations and filling questionnaires. Worker posture and mechanical vibration were measured by the REBA assessment method, as well as the occurrence of musculoskeletal disorders (MSDs) complaints measured via the Nordic Body map (NBM) sheet filling. Data was analyzed using the Spearman correlation test. Results: Spearman test correlation suggests that there is a significant link between the musculoskeletal disorder complaints with the work posture $p=0.000 ; r=0.819$ and mechanical vibration $p=0.000 ; r=0.951$. The influence of work posture and mechanical vibration in the complaint of musculoskeletal disorders as much as $91.8 \%$. Conclusion: there are a significant relationship and influence between work posture and mechanical vibration with the complaint of musculoskeletal disorders.
\end{abstract}

Keywords: musculoskeletal disorder complaints; working posture; mechanical vibration

Copyright $\odot 2013$ Universitas Ahmad Dahlan. All rights reserved.

\section{Pendahuluan}

Musculoskeletal disorder merupakan masalah kesehatan yang berhubungan dengan pekerjaan dapat terjadi di seluruh dunia dan menjadi salah satu penyebab ketidakhadiran pekerja. Kasus musculoskeletal disorder tercatat $80 \%$ terjadi pada pekerja industri swasta manufaktur seperti tekstil.(1) Prevalensi keluhan musculoskeletal disorder pada tahun $2013 \mathrm{di}$ Indonesia berdasarkan diagnosis tenaga kesehatan yaitu $11,9 \%$ dan berdasarkan diagnosis atau gejala yaitu $24,7 \%$. Sedangkan, Prevalensi musculoskeletal disorder pada tahun 2018 di Jawa Tengah yaitu $7,3 \%$.(2) Industri tekstil memiliki fakor risiko yang berdampak kurang baik seperti aktivitas pekerjaan yang menuntut pekerja berdiri, melakukan gerakan berulang, bekerja dengan punggung membungkuk dan terdapat faktor bahaya dari lingkungan kerja yaitu getaran.(3) Faktor risiko tersebut mengakibatkan pekerja melakukan aktivitas dengan postur kerja yang tidak alamiah, sehingga dapat menimbulkan keluhan musculoskeletal disorder.(4,5) PT Bintang Makmur Sentosa Tekstil Industri (BMSTI) Sragen terletak di Jl. Raya Timur Km. 8 Karanganyar, Sambung Macan, Sragen, Jawa Tengah. PT Bintang Makmur Sentosa Tekstil Industri sudah berdiri selama 10 tahun yang memiliki 3 unit produksi yaitu winding, TFO, dan spinning.

Berdasarkan survai awal yang telah dilakukan pada unit spinning di PT BMSTI menggunakan kuesioner Nordic Body Map dengan metode wawancara dari 12 pekerja sebanyak 11 pekerja mengalami keluhan musculoskeletal disorder dengan kategori ringan (6 
pekerja) dan sedang (5 pekerja) terutama pada bagian leher atas $(66,6 \%)$, punggung $(58,2 \%)$, kaki $(66,6 \%)$, pergelangan kaki $(66,6 \%)$, dan betis $(58,3 \%)$, sedangkan 1 orang pekerja tidak mengalami keluhan musculoskeletal disorder. Pengukuran postur kerja pada 8 pekerja unit spinning menggunakan metode Rapid Entire Body Assesment (REBA) menunjukan pekerja melakukan aktivitas pekerjaan dengan postur kerja kategori sedang. Pengukuran getaran mekanis jenis whole body vibration unit spinning menggunakan Vibration meter pada 3 titik lokasi pengukuran memiliki nilai rata - rata acceleration di atas nilai ambang batas yaitu 0,93 $\mathrm{m} / \mathrm{s}^{2}$,(3) sehingga meningkatkan risiko terjadinya keluhan musculoskeletal disorder. Oleh karena itu, peneliti tertarik melakukan penelitian dengan tujuan untuk mengetahui hubungan postur kerja dan getaran mekanis dengan keluhan musculoskeletal disorder pada pekerja unit spinning di PT Bintang Makmur Sentosa Tekstil Industri.

\section{Metode}

Penelitian dilaksanakan di PT Bintang Makmur Sentosa Tekstil Industri (BMSTI) Sragen pada bulan Januari 2019 sampai Juni 2019. Penelitian ini merupakan penelitian analitik observasional untuk menganalisis hubungan antar variabel dengan menggunakan desain penelitian cross sectional, karena setiap variabel diamati pada waktu yang bersamaan. Besar sample yang diambil dalam penelitian ini menggunakan seluruh total populasi pekerja pada unit spinning di PT Bintang Makmur Sentosa Tekstil Industri (BMSTI) Sragen yang berjumlah 110 orang. Analisis data pada penelitian ini dilakukan untuk menganalisis hubungan antara postur kerja dan tekanan mekanis dengan kejadian keluhan Musculoskeletal Disorders (MSDs) pada pekerja dengan menggunakan uji kolerasi dari spearman

\section{Hasil dan Pembahasan}

3.1. Hasil

3.1.2. Karakteristik responden

Hasil penelitian yang telah dilakukan pada unit spinning di PT BMSTI yang diperoleh menunjukkan bahwa dari 110 responden paling tinggi berumur $36-45$ tahun $(36,4 \%)$ berjenis kelamin perempuan $(75,5 \%)$ dengan indeks masa tubuh kegemukan $(68,2 \%)$ dan tidak pernah melakukan olahraga $(77 ., \%)$. Selain itu, $<5$ tahun $(60 \%)$ responden yang memilki masa kerja dan $(91,8 \%)$ tidak memiliki riwayat penyakit sendi atau otot. Secara rinci dapat dilihat pada Tabel 1.

Tabel 1. Karakteristik Responden Penelitian

\begin{tabular}{|c|c|c|}
\hline Variabel & $\mathbf{n}$ & $\%$ \\
\hline \multicolumn{3}{|l|}{ Umur } \\
\hline 17-25 tahun & 19 & 17,3 \\
\hline $26-35$ tahun & 38 & 34,5 \\
\hline 36-45 tahun & 40 & 36,4 \\
\hline 46-55 tahun & 13 & 11,8 \\
\hline \multicolumn{3}{|l|}{ Jenis Kelamin } \\
\hline Laki - laki & 27 & 24,5 \\
\hline Perempuan & 83 & 75,5 \\
\hline \multicolumn{3}{|l|}{ Indeks Masa Tubuh } \\
\hline Kurus & 1 & 0,09 \\
\hline Normal & 34 & 30,9 \\
\hline Kegemukan & 75 & 68,2 \\
\hline \multicolumn{3}{|l|}{ Kebiasaan Olahraga } \\
\hline Ya & 25 & 22,7 \\
\hline Tidak & 85 & 77,3 \\
\hline \multicolumn{3}{|l|}{ Masa Kerja } \\
\hline$<5$ & 66 & 60 \\
\hline $5-10$ & 44 & 40 \\
\hline$>10$ & 0 & 0 \\
\hline \multicolumn{3}{|c|}{ Riwayat Penyakit Persendian/Otot } \\
\hline Ya & 9 & 8,2 \\
\hline Tidak & 101 & 91,8 \\
\hline
\end{tabular}

Disease Prevention and Public Health Journal

Volume 14, Issue 1, March 2020: $1 \sim 5$ 
3.1.2. Postur Kerja dengan Keluhan Musculoskeletal Disorders (MSDs)

Hasil yang disajikan Tabel 2. menunjukkan bahwa ada hubungan signifikan antara postur kerja $(p$-value $<0,05)$ dan getaran mekanis $(p$-value $<0,05)$ terhadap keluhan musculoskeletal disorders. Adapaun variabel postur kerja dan getaran mekanis memiliki pengaruh terhadap keluhan musculoskeletal disorder dengan proporsi $91,8 \%$.

Tabel 2. Hasil Analisis Multivariat Postur Kerja dan Getaran Mekanis dengan Musculoskeletal Disorders (MSDs)

\begin{tabular}{lccc}
\hline \multirow{2}{*}{ Variabel } & \multicolumn{3}{c}{ MSDs } \\
\cline { 2 - 4 } & $\boldsymbol{p}$ value & $\mathbf{R}$ & $\begin{array}{c}\boldsymbol{R} \\
\text { Square }\end{array}$ \\
\hline Postur kerja & 0,000 & 0,819 & 0,918 \\
Getaran Mekanis & 0,000 & 0,951 & \\
\hline
\end{tabular}

MSDs : Musculoskeletal Disorder

\subsection{Pembahasan}

Pekerja bagian spinning yang berusia pada rentang 36-45 tahun. Menurut Depkes (2018) umur produktif yaitu antara 15-64 tahun, dalam penelitian ini umur responden antara 20 - 50 tahun, sehingga termasuk umur kerja produktif.(2) Meskipun masih tergolong umur kerja produktif, seluruh responden mengalami keluhan musculoskeletal disorder pada tingkat risiko rendah, sedang, dan tinggi. Hal tersebut selaras dengan penelitian sebelumnya yang menunjukkan bahwa keluhan musculoskeletal disorder terjadi pada umur muda dan sebagian besar menyerang pada umur produktifdengan berbagai tingkat risiko.(6) Namun, dalam penelitian ini terdapat 1 responden pada umur 46-55 tahun mengalami keluhan musculoskeletal disorder tingkat risiko rendah sebab memiliki IMT kategori normal dan melakukan aktivitas kerja dengan postur kerja kategori rendah. Jenis kelamin responden sebagian besar adalah perempuan $(75.5 \%)$ dan pada saat dilakukan penelitian terdapat 30 responden (36.1\%) sedang mengalami siklus menstruasi dan mengeluhkan rasa nyeri atau sakit pada bagian pinggang serta terdapat 11 responden (13.3\%) yang memiliki umur $>45$ tahun sudah mengalami menopause sehingga dapat menyebabkan kepadatan tulang berkurang dan lebih berisiko untuk mengalami keluhan musculoskeletal disorder.

Responden laki - laki (9.1\%) juga mengalami keluhan musculoskeletal disorder tingkat risiko rendah sebab memiliki IMT normal dan memiliki kebiasaan olahraga secara rutin. Sedangkan, terdapat 16 responden laki - laki (14.5\%) mengalami keluhan musculoskeletal disorder tingkat risiko sedang sebab tidak memiliki kebiasaan olahraga dan melakukan aktivitas kerja dengan postur kerja kategori sedang. Indeks masa tubuh responden sebagian besar pada kategori kegemukan (68.2\%) dengan posisi kerja berdiri, menyebabkan tekanan tulang belakang dapat mencapai $100 \%$ serta bagian tubuh yaitu kaki harus menyangga tubuh dalam waktu 8 jam kerja, sehingga indeks masa tubuh yang berlebih meningkatkan risiko keluhan musculoskeletal disorder. $(7,8)$ Jumlah responden yang tidak melakukan olahraga cukup banyak yaitu $77,3 \%$ karena selesai bekerja responden sudah merasa kelelahan, sedangkan sebelum mulai bekerja responden juga tidak melakukan aktivitas olahraga sebab waktu yang ada lebih diprioritaskan untuk persiapan kerja sehingga tidak memiliki waktu untuk berolahraga. Responden penelitian melakukan olahraga dengan frekuensi 1-3 kali dalam seminggu dengan jenis olahraga senam bagi responden perempuan dan futsal, badminton, dan lari bagi responden laki laki. Keluhan musculoskeletal disorder tingkat rendah, sedang, dan tinggi sebagian besar dialami oleh responden yang tidak melakukan kebiasaan olahraga. Hal tersebut sejalan dengan penelitian lainnya yang menunjukkan pekerja yang tidak terbiasa melakukan aktivitas fisik lebih berisiko mengalami keluhan musculoskeletal disorder.(9) Masa kerja responden penelitian sebagian besar $<5$ tahun $(66 \%)$. Masa kerja tersebut telah mampu memberikan kontribusi terhadap munculnya keluhan musculoskeletal disorder. Hal tersebut disebabkan oleh otot responden yang belum terbiasa melakukan aktivitas pekerjaan. Sedangkan seagian responden yang memilki masa kerja 5-10 tahun (44\%) sudah mampu beradaptasi dengan proses kerja yang mengganggu kerja otot.(10) Responden yang memiliki riwayat penyakit persendian sebanyak $8,2 \%$ sedagkan yang tidak mengalami riwayat penyakit persendian sebanyak 101 responden (91.8\%). Hasil 
penelitian ini bertolak belakang dengan penelitian yang dilakukan oleh Safitri menunjukkan seseorang dengan riwayat penyakit persendian atau otot mempunyai kecenderungan untuk mengalami kejadian lanjutan.(11)

Penilaian postur kerja dengan menggunakan metode Rapid Entire Body Assesment (REBA) diperoleh hasil nilai rata - rata skor postur kerja responden penelitian unit sebesar 5 dengan kategori risiko sedang. Responden memiliki salah satu aktivitas kerja yaitu mengambil gulungan benang pada bobin dan meletakkan bobin pada spindel. Hasil pengukuran getaran mekanis jenis whole body vibration pada mesin spinning dan lantai unit spinning diperoleh nilai rata - rata percepatan getaran yaitu $0,96 \mathrm{~m} / \mathrm{s}^{2}$. nilai rata - rata percepatan getaran berada di atas nilai ambang batas. Hal tersebut dapat terjadi karena perusahaan belum pernah melakukan pengukuran getaran mekanis secara berkala dan penggunaan mesin spinning yang sudah mencapai 10 tahun sehingga nilai percepatan getaran yang dihasilkan oleh mesin cukup tinggi. Hasil penelitian terkait keluhan musculoskeletal disorder menunjukkan Keluhan paling tinggi pada bagian kaki karena postur kerja responden penelitian dalam melakukan aktivitas adalah berdiri selama 8 jam dan berjalan dari mesin ring spinning yang satu ke yang lainnya. Hasil uji pearson product moment menunjukkan ada hubungan yang signifikan dan tingkat hubungan sangat kuat antara variabel postur kerja dengan keluhan musculoskeletal disorder. Penelitian ini selaras dengan sebelumnya yang menunjukkan ada hubungan signifikan antara postur kerja dengan keluhan musculoskeletal disorder.(11) Postur kerja responden penelitian yang tidak ergonomis, menyebabkan posisi bagian - bagian tubuh bergerak menjauhi posisi alamiah dan pusat gravitasi, sehingga semakin tinggi risiko terjadinya keluhan musculoskeletal disorder.(10)

Hasil penelitian menunjukkan ada hubungan yang signifikan antara variabel getaran mekanis dengan keluhan musculoskeletal disorder. Hasil penelitian tersebut selaras dengan penelitian sebelumnya yang menunjukkan ada hubungan signifikan antara getaran dan keluhan musculoskeletal.(14,15) Getaran yang bersumber dari mesin spinning berupa getaran jenis whole body vibration yang menjalar ke tubuh melalui kaki dan tangan, sehingga responden mengeluhkan nyeri terutama pada bagian kaki.(3) Nilai rerata percepatan getaran mekanis jenis whole body vibration juga melebihi nilai ambang batas sehingga meningkatkan risiko keluhan musculoskeletal disorder. Sedangkan hasil uji hubungan postur kerja dan getaran mekanis memiliki proporsi pengaruh $91,8 \%$ terhadap keluhan musculoskeletal disorder sedangkan sisanya $8,2 \%$ dipengaruhi oleh variabel lain seperti jenis kelamin, umur, indeks masa tubuh, masa kerja, lama kerja, riwayat penyakit persendian atau otot, dan kebiasaan olahraga. Postur kerja dan getaran mekanis mempunyai pengaruh yang cukup tinggi terhadap keluhan musculoskeletal disorder dapat disebabkan oleh beberapa postur kerja responden yang tidak alamiah seperti punggung membungkuk, kepala menunduk, melakukan gerakan berulang pada pergelangan tangan dan responden juga terpapar getaran mekanis jenis whole body vibration dengan nilai percepatan yang melebihi nilai ambang batas selama 8 jam dalam sehari. $(3,12)$

\section{Kesimpulan}

Terdapat hubungan yang signifikan antara postur kerja, getaran mekanis dengan keluhan musculoskeletal disorder dengan nilai proporsi sebesar $91,8 \%$.

\section{Daftar Pustaka}

1. Bureau of Labour Statistic. Nonfatal Occupational Injuries and IIInesses Requiring Days Away from Work, 2015. United States of America: Department of Labor; 2016.

2. Martini S, Roshifanni S, Marzela F. Pola Tidur yang Buruk Meningkatkan Risiko Hipertensi. Media Kesehat Masy Indones. 2018;14(3):297.

3. Raffler N, Ellegast R, Kraus T, Ochsmann E. Factors affecting the perception of whole-body vibration of occupational drivers: an analysis of posture and manual materials handling and musculoskeletal disorders. Ergonomics. 2016;59(1):48-60.

4. K. Davis KD G Jewell and J Lockey. Cost and disability trends of work-related musculoskeletal disorders in Ohio. Occup Med. 2014;64:608-615. 
5. Charles LE, Ma CC, Burchfiel CM, Dong RG. Vibration and Ergonomic Exposures Associated With Musculoskeletal Disorders of the Shoulder and Neck. Saf Health Work. 2018;9(2):125-32.

6. Nuryaningtyas and Martiana. Analisis Tingkat Risiko Muskuloskeletal Disorders (MSDs) Dengan The Rapid Upper LIMBS Assessment (RULA) dan Karakteristik Individu Terhadap Keluhan MSDs. Indones J Occup Saf Health. 2014;3:160-9.

7. Sandi PR, Ekawati S. Pengaruh Karakteristik Pekerja Terhadap Kejadian Musculoskeletal Disorder Pada Pekerja Pabrik Tenun Masari Pemalang. J Kesehat Masy E-J. 2015;3(1):429-36.

8. Djaali NA Meidy Putri Utami. Analisis Keluhan Musculoskeletal Disorders (MSDs) pada Karyawan PT. Control System Arena para Nusa. J IIm Kesehat. 2019;11(1):80-7.

9. Abraha TH, Demoz AT, Moges HG, Ahmmed AN. Predictors of back disorder among Almeda textile factory workers, North Ethiopia. BMC Res Notes. 2018;11(1).

10. Santosa A Dwi Kuat Ariska. Faktor-Faktor yang Berhubungan dengan Kejadian Musculoskeletal Disorders pada Pekerja Batik di Kecamatan Sokaraja Banyumas. MEDISAINS J IIm IImu-IImu Kesehat. 2018;16(1):42-6.

11. Safitri A EP. Faktor - Faktor yang Berhubungan dengan Kejadian Musculoskeletal Disorders (MSDs) di Bagian Finishing Unit Coating PT. Pura Barutama Kudus. J Keperawatan Dan Kesehat Masy. 2017;2(5).

12. Sulistiyo TH Rico J Sitorus, Ngudiantoro. Analisis faktor risiko ergonomi dan musculoskeletal disorders pada radiografer instalasi radiologi rumah sakit di kota palembang. J Kedokt Dan Kesehat. 2018;5(1):26-37.

13. Susanti DEL, Hilma Raimona Zadry P., Berry Yuliandra M. Pengantar Ergonomi Industri. 2015;(May):30.

14. Enrico J. M Paul AT Kawatu, Grace D Kandou. Hubungan Antara Umur, Lama Kerja, dan Getaran dengan Keluhan Muskuloskeletal pada Supir Bus Bus Trayek Bitung-Manado di Terminal Tangkoko Bitung Tahun 2016. J Ilm Farm. 1 Februari 2016;5(1):297-302.

15. Astuti, R. SSR Suharni A Fachrin. Analisis Hubungan Postur Kerja dengan Keluhan Muskuloskeletal terhadap Kinerja Karyawan di PT. Bri Cab Panakkukang Makassar Tahun 2018. J IIm Kesehat Diagn. 2019;14(1):21-5. 